\title{
A Arqueologia na formação do museólogo: um olhar a partir do Curso de Museologia (1932-2010)
}

Alejandra Saladino ${ }^{1}$

Guilherme de Almeida Machado ${ }^{2}$

\section{Resumo}

Desde 1932, o Curso de Museologia, originalmente vinculado ao Museu Histórico Nacional (MHN/Ibram/MinC) e, desde 1979, integrante da Universidade Federal do Estado do Rio de Janeiro (UNIRIO), compromete-se com o desafio de formar profissionais para atuar na preservação, investigação e comunicação do patrimônio museológico do país. O Grupo de Investigação "Memória e Preservação da Museologia no Brasil", coordenado pelo Prof. Dr. Ivan Coelho de Sá (CCHS/UNIRIO), vem desenvolvendo estudos com o intuito de compreender a conformação do campo da Museologia e refletir sobre percursos a seguir. Nesse sentido, foi desenvolvida uma investigação com vistas a perceber o lugar da Arqueologia na formação dos museólogos, a partir da análise das grades curriculares do Curso de Museologia fundado em 1932. O objetivo deste artigo é precisamente apresentar alguns dos resultados obtidos com o desenvolvimento do referido estudo, dentre os quais destacam-se a constatação da importância do estudo dos fundamentos da Arqueologia na formação dos museólogos, o que contribuiu para a criação de profissionais que

\footnotetext{
${ }^{1}$ Museóloga, professora adjunta do Departamento de Estudos e Processos Museológicos (CCHS/UNIRIO), professora colaboradora do Mestrado Profissionalizante em Preservação do Patrimônio Cultural (Centro Lúcio Costa/IPHAN) e do Programa de Pós-Graduação em Museologia e Patrimônio (PPGP-MUS/UNIRIO) e museóloga do Museu da República (MR/Ibram/MinC). alejandrasaladino@gmail.com ${ }^{2}$ Graduando no Curso de bacharelado em Museologia da Universidade Federal do Estado do Rio de Janeiro - UNIRIO.
} 
não apenas atuaram em ambos os campos de conhecimento mas, sobretudo, na preservação do patrimônio arqueológico.

Palavras-chave: Museologia; Arqueologia; formação de museólogos

\begin{abstract}
Since 1932, the Museum Studies Course, originally linked to the National History Museum (MHN / Ibram / Ministry of Culture ) and, since 1979, member of the Federal University of the State of Rio de Janeiro ( UNIRIO ), is committed to the challenge of training professionals to act in the preservation, research and communication of the museum heritage of the country. The research group "Memory and Museology Preservation in Brazil, coordinated by Prof. Dr. Ivan Coelho de Sá ( CCHS / UNIRIO ), has been conducting studies in order to understand the configuration of the field of Museology and reflect on the following routes. In this sense, a research was developed in order to realize the place of archeology in the training of museum experts from the analysis of the curricula of Museology course founded in 1932. The purpose of this article is precisely to present some of the results obtained with the development of the study, among which is the realization of the importance of the study of the foundations of archeology in the training of museum experts, which contributed to the creation of professionals who not only worked in both fields of knowledge but, above all, the preservation of archaeological heritage.
\end{abstract}

Keywords: Museology; Archaeology; course of museologists

\title{
Apresentação
}

Os museus se consolidaram no Ocidente como espaços produtores de sentidos e de conhecimento (SCHWARCZ, 2003; GONÇALVES, 2002; BRUNO, 2005; SALADINO, 2010; WICHERS, 2010). Lugares de memória (NORA, 1993) e berços das disciplinas científicas, é possível considerá-los como espaços de legitimação de discursos e representações.

O discurso do patrimônio cultural tem no museu um lugar estratégico de ressonância. No Brasil, esta construção narrativa oficial (tecida na trama do campo político, jurídicolegal, científico, social e econômico) tem suas bases associadas à 
institucionalização das práticas de preservação, com a criação do então Serviço do Patrimônio e Histórico Nacional (hoje Instituto, do Patrimônio e Histórico Nacional), em 1937 (FONSECA, 2005; SANTOS, 2000; CHAGAS, 2006).

Ainda que tomando por base o anteprojeto para a criação de um órgão federal para proteção e preservação do patrimônio cultural brasileiro de autoria de Mário de Andrade, que partia de uma visão histórico-antropológica mais ampla das referências patrimoniais, as práticas e políticas de preservação, de início, priorizaram algumas referências, muitas delas associadas à matriz cultural luso-católica. Neste momento, a ancestralidade não foi um valor marcante na construção da identidade nacional a partir da valorização das referências patrimoniais da sociedade brasileira.

Graças ao estudo de doutorado, realizado no Programa de Pós-Graduação em Ciências Sociais da Universidade do Estado do Rio de Janeiro à luz do institucionalismo histórico, percebemos que as primeiras escolhas institucionais foram determinantes para a construção da trajetória do IPHAN e para o delineamento de suas práticas e instrumentos de preservação (SALADINO, 2010). Assim sendo, consideramos que a pouca atenção dada às referências patrimoniais dos sistemas culturais pré-coloniais (em relação a outras manifestações, notadamente associadas ao período colonial) teve grande influência nos padrões institucionais posteriormente estabelecidos, bem como no lugar da preservação do patrimônio arqueológico $n$ trajetória do IPHAN (considerando aspectos como o desenho institucional, o quadro funcional e a dotação orçamentária).

A Profa. Dra. Cristina Bruno também percebe a ausência das fontes arqueológicas nas análises sobre a formação da 
identidade nacional. Tal fenômeno é definido pela autora como estratigrafia do abandono, responsável pelo esquecimento das fontes arqueológicas e pela sua circunscrição no terreno das memórias exiladas (BRUNO, 1999: 23). Bruno segue afirmando que exílio das referências patrimoniais arqueológicas, somado à ideia de que os processos preservacionistas representam oposição ao progresso (BRUNO, 1999: 28) torna mais complexa a referida estratigrafia do abandono.

Voltando ao museu e seu potencial para a decodificação e legitimação de discursos, é possível perceber com clareza o seu lugar estratégico na valorização de memórias e representações marginalizadas. Assim sendo, partimos do pressuposto de que os museus podem ser instituições-chave para a apropriação, valorização e preservação do patrimônio arqueológico.

Este argumento foi o condutor do projeto de investigação "A Arqueologia na formação do museólogo: um olha a partir do curso de Museologia (1932-2010)", cuja apresentação e exposição dos resultados motivaram a realização do presente artigo.

O projeto de investigação "A Arqueologia na formação do museólogo: um olha a partir do curso de Museologia (19322010)": estrutura e resultados alcançados

A investigação, realizada ao longo do ano de 2013, foi, em conformidade com os protocolos do Departamento de Investigação da UNIRIO, subdividida no subprojeto "Arqueologia para museólogos: os docentes do Curso de Museus (193212010)" - desenvolvida pelo bolsista de iniciação científica, Guilherme Machado. O estudo, vinculado ao Grupo de 
Investigação "Memória e Preservação da Museologia no Brasil, coordenado pelo Prof. Dr. Ivan Coelho de Sá, e à Linha de Investigação "Museus e Museologia" do Curso de Museologia (CCHS/UNIRIO), pode, portanto, ser compreendido como o aprofundamento de um tema específico da memória do campo disciplinar em tela.

A questão norteadora do estudo ora apresentado foi: a graduação em Museologia prepara, concreta e efetivamente, os profissionais para enfrentarem o desafio da preservação do patrimônio arqueológico musealizado? Ou seja, a questão que subjacente a essa foi como a Arqueologia se apresenta no ensino da Museologia?

Todavia, foi possível elencar outras questões:

- de que maneiras - objetivas e concretas - a formação em Museologia pode contribuir para com a ressignificação e valorização do patrimônio arqueológico? Em outras palavras, quais as ferramentas e métodos aplicados pelos museólogos para dar sentido a fragmentos de objetos de culturas extintas e do nosso passado recente?

- de que maneira a formação do museólogo no país aborda os desafios da musealização do patrimônio arqueológico em tempos da arqueologia de contrato - quando os acervos arqueológicos crescem em escala exponencial (BRUNO \& ZANETTINI, 2007) - e das políticas públicas voltadas para o investimento no turismo cultural, muitas vezes predatório? Em outras palavras, como a Museologia capacita profissionais aptos a participar de programas de gestão do patrimônio arqueológico?

- a formação do museólogo é interdisciplinar em que nível? Dito de outra forma, o estudante de museologia articula os 
princípios teóricos e metodológicos da Museologia com a Arqueologia, especialmente a Arqueologia Pública?

Propusemos então a reflexão sobre tais questões a partir de um contexto específico: o Curso de Museologia da UNIRIO. Tal curso foi criado em 1932 pelo Decreto no 21.129/32 com o objetivo de formar profissionais aptos a lidar com as especificidades e os desafios da preservação do patrimônio cultural brasileiro do Museu Histórico Nacional, sede do referido curso, foi concebido por Gustavo Barroso.

O curso, concebido inicialmente para formação técnica, contou em seu corpo docente com especialistas na curadoria de coleções, atores-chave para a constituição de alguns campos do conhecimento como, por exemplo, o Professor Angyone Costa diletante da Arqueologia, autor do primeiro livro didático dessa disciplina científica publicado no país. A referência em questão, intitulada Archeologia Geral: civilizações da América PréColombiana, Antiguidade Clássica, Civilizações Orientaes (COSTA, 1936), foi desenvolvida para atender às especificidades da formação dos museólogos no que se referia à curadoria das coleções arqueológicas. Desde então, a Arqueologia faz parte da formação dos museólogos no referido curso que, na década de 1970, passou a integrar a UNIRIO.

O universo analisado compreendeu a fatia temporal que vai desde a criação do curso até a última reforma curricular instituída, em 2010.

Definido o contexto a analisar, surgiram outras questões:

- por que a Arqueologia constituiu cadeira obrigatória nas grades curriculares do Curso de Museologia desde sua criação? 
- que conteúdos referentes a essa área do conhecimento eram debatidos nas cadeiras oferecidas?

- esses conteúdos refletem os avanços dos estudos no âmbito da Arqueologia Brasileira?

- de que forma era tratada a questão da curadoria das coleções arqueológicas e da preservação do patrimônio arqueológico?

A intenção de dedicar uma investigação ao entendimento do processo formativo dos museólogos no que tange a curadoria das coleções arqueológicas e à preservação do patrimônio arqueológico como um todo originou da percepção de que os referidos profissionais, enquanto agentes de preservação, ressignificação e mediação do patrimônio cultural, têm um papel importante na difusão do conhecimento arqueológico e na apropriação dessa categoria de patrimônio.

O objetivo geral deste projeto concentrou-se na análise da formação dos museólogos do Curso de Museus no que tange a identificação e gestão do patrimônio arqueológico brasileiro, desde sua fundação até 2010, quando da implantação da última reforma curricular. Já os objetivos específicos foram:

- compor um perfil dos professores responsáveis pelas cadeiras de Arqueologia;

- analisar as ementas e os conteúdos programáticos de todas as cadeiras do Curso de Museologia da UNIRIO voltadas para a arqueologia e a gestão e curadoria das coleções arqueológicas;

- analisar os projetos político-pedagógicos dos cursos de Museologia que tiveram como modelo o projeto da escola de Museologia da UNIRIO o perfil/conteúdo programático das cadeiras que tratam da relação entre a arqueologia e o mundo dos museus. 
A metodologia deste estudo caracterizou-se por uma abordagem quantitativa e qualitativa, pois se fez necessário um levantamento das alterações de carga horária das cadeiras cujo conteúdo programático constava a Arqueologia para tornar possível refletir sobre a formação do museólogo no tocante aos desafios da preservação do patrimônio arqueológico levando em consideração o próprio panorama, ou seja, as demandas relativas à ressignificação dos acervos arqueológicos nas exposições e à gestão do patrimônio arqueológico na era da arqueologia de contrato.

O objetivo geral deste subprojeto foi contribuir para compor uma trajetória do ensino da Arqueologia na Escola de Museologia, desde sua criação até o ano da implantação da última reforma curricular, 2010. A intenção foi fornecer subsídios para compreender, a partir dos conteúdos programáticos e do perfil profissional dos professores responsáveis pela elaboração dos referidos conteúdos, as linhas da Arqueologia e da Museologia consideradas na formação dos profissionais.

De início, foi realizado um levantamento bibliográfico acerca do desenvolvimento da Arqueologia enquanto campo científico no Brasil - do qual se destaca o livro de Arqueologia Brasileira, de André Prous (1992) - e sobre o curso de Museologia - do qual se destaca o artigo de Ivan Coelho de Sá (SÁ, 2012) e o Trabalho de Conclusão de Curso de Natália Figuerêdo (FIGUEIRÊDO, 2013). Além disso, para compreender os conteúdos programáticos e ementas das cadeiras de arqueologia ministradas pelo Professor Angyone Costa, fez-se a leitura de sua já referida (COSTA, 1936).

Após a revisão bibliográfica sobre a constituição das disciplinas Arqueologia e Museologia no Brasil em relação às 
demandas do campo do patrimônio (métodos e instrumentos de preservação, especificamente do patrimônio arqueológico), foram desenvolvidas as seguintes atividades:

- levantamento documental sobre as cadeiras de Arqueologia no Curso de Museologia e seus responsáveis. A intenção era perceber, a partir dos conteúdos programáticos e do perfil profissional dos professores responsáveis pela elaboração dos referidos conteúdos, as linhas da Arqueologia e da Museologia consideradas na formação dos profissionais com vistas à sua capacitação enquanto gestores do patrimônio arqueológico, responsáveis pela aplicação da cadeia operatória da museologia sobre tais bens e colaboradores para sua ressignificação, apropriação e valorização por parte da sociedade e - elaboração de um panorama sobre o desenvolvimento da Arqueologia e da preservação do patrimônio arqueológico no Brasil para analisar a atuação e contribuição do museólogo na preservação e gestão dessa categoria de bem.

Considerando o campo das ciências humanas no século $X X$, optou-se por ampliar o universo estudado para os professores e disciplinas correlatas, ou seja, além da Arqueologia, foram incluídas as disciplinas de Etnografia, de Antropologia e de Folclore. Isto para verificar se os temas da Arqueologia eram trabalhados em disciplinas além da Arqueologia Geral.

O levantamento das fontes primárias, nomeadamente matrizes curriculares, projetos político-pedagógicos e ementas das cadeiras, se configurou como etapa da investigação desenvolvida sem problemas, pois as fontes estavam reunidas no arquivo do Grupo de Investigação ao qual vinculou-se o estudo em tela. O desafio concentrou-se no levantamento dos dados 
para composição dos perfis dos professores responsáveis pelas cadeiras de Arqueologia.

O levantamento do Fundo "Leis, Decretos, Pareceres, Resoluções, Portarias, Ofícios, Estatutos, Regimentos e outros", e das Matrizes Curriculares de 1932 a 2010 levou aos seguintes resultados:

- Apesar das sucessivas mudanças na grade curricular do Curso não houve significativas alterações na carga horária das disciplinas de Arqueologia (90h). A carga só reduziu nas sucessivas alterações ocorridas na década de 1970, quando passou para 45h. Mas foi apenas na reforma de 1996 que a carga que se deu a distribuição em $45 \mathrm{~h}$ obrigatórias (Arqueologia Geral) e 45h optativas (Arqueologia Pré-Hispânica e Brasileira);

- A reforma de 1944 (em vigor, de 1945 a 1966) estabeleceu o regime de pré-requisito para a cadeira Arqueologia. Para cursar Arqueologia Brasileira (90h), na Seção Museus Históricos (ano 3), era preciso antes cursar Etnografia (90h) que, por sinal, tinha o conteúdo programático da disciplina a Arqueologia I (90h) da matriz anterior. Para cursar Arqueologia Brasileira, Arte Indígena e Arte Popular (90h), na Seção Museus Artísticos (ano 3), igualmente era preciso ter cursado Etnografia I.

- A reforma de 1966, em vigor de 1967 a 1969, manteve a relação entre as disciplinas acima mencionadas apontadas;

- As mudanças mais significativas ocorreram a partir da matriz curricular experimental de 1970, com a criação de Etnografia do Brasil (45h) e Introdução à Etnologia, ambas pré-requisitos para cursar as disciplinas de Arqueologia. Por sua vez, as cadeiras supracitadas deviam ser cursadas após Antropologia I (15h) e Antropologia II (15h). Outra alteração significativa dessa matriz curricular experimental se deu na seção Museus Científicos, pois, 
a partir de então, para cursar Arqueologia do Brasil (45h) e Arqueologia de Campo I e II (45h) era necessário antes cursar Paleontologia;

- Uma nova proposta de alteração que afetou o ensino da Arqueologia no Curso de Museus se observa na Matriz Curricular de 1971. Arqueologia (90h), do tronco comum e cursada no ano 3, teria como pré-requisitos as disciplinas Introdução à Antropologia - ex Antropologia I e II da Matriz experimental de 1970 - (60h), no ano 1, e, no ano 2, Introdução à Etnologia - ex Antropologia III e IV da Matriz experimental de 1970 - (90h);

- As sucessivas reformas curriculares ocorridas na década de 1970 demonstram as disciplinas Antropologia como prérequisitos para cursar Arqueologia. Somente na matriz curricular implantada em 1997, em vigor até o ano de 2007, a cadeira Arqueologia Geral (2o período - 45h) deixou de ter pré-requisito;

- Foi possível observar na última reforma curricular, implantada em 2010, o aumento da área de interseção entre Arqueologia e Museologia. Em outras palavras, ganhou espaço o tema da preservação do patrimônio arqueológico com a criação de duas disciplinas optativas, Musealização do Patrimônio Arqueológico (45h) e Conservação de Coleções Arqueológicas (60h).

Quanto ao fundo das ementas de cada disciplina, dispostas em ordem cronológica, existem muitas lacunas, e conforme se retrocede ao ano de 1932, essas ausências aumentam.

A análise das ementas encontradas resultou nos seguintes resultados:

- Em toda a história do Curso de Museus e de Museologia, no ensino da disciplina de Arqueologias foram passados aos discentes conteúdos referentes à conceituação, à definição, aos 
métodos e às divisões, assim como sua ligação com outras áreas do conhecimento;

- Da década de 1930 à década de 1970, aos conteúdos mencionados, somaram-se os referentes à Arqueologia Clássica, à Pré-história, à Pré-história do continente americano, à evolução do Homo sapiens e sua dispersão pelo planeta, ao estudo de povos àquela altura considerados primitivos, à formação das grandes civilizações (com ênfase para as culturas americanas, nomeadamente a Inca, Maia e Asteca), aos povos pré-coloniais assentados no território brasileiro (com ênfase no estudo de vestígios rupestres, cerâmica e sambaquis), e ao estudo de áreas afins, como fundamentos Geológicos da Arqueologia, Fundamentos Paleontológicos da Arqueologia e Fundamentos Antropológicos da Arqueologia, comprovando que o ensino da Arqueologia inicialmente estava ligado à disciplinas como Geologia, Paleontologia, Antropologia e Etnografia;

- A partir da década de 1980, as ementas passam a dar ênfase ao estudo do continente americano, especialmente dos povos e culturas assentados no território brasileiro;

- A partir da segunda metade da década de 1990, acompanhando as mudanças ocorridas no campo da Arqueologia, o ensino de tal disciplina passou enfatizar os temas da construção da Arqueologia como disciplina científica, do desenvolvimento de suas perspectivas teóricas e de seus métodos. Além disso, passou-se a valorizar a função do arqueólogo junto à sociedade, a importância na análise da evidência científica e como apoio à interpretação do desenvolvimento sociocultural da humanidade, sua relação com as ciências sociais, e não somente com as ciências naturais, ou seja, a interdisciplinaridade, e a aplicação do trabalho arqueológico nos museus; 
- A partir de 2004, com a contratação de professores substitutos, os conteúdos programáticos e bibliografias das cadeiras Arqueologia Geral e Arqueologia Pré-Hispânica demonstraram maior correspondência com o campo da Arqueologia. Dito de outra forma, nas disciplinas passaram a ser apresentados e discutidos temas mais atualizados e em consonância com os estudos no âmbito da Arqueologia Brasileira;

- em 2008, as cadeiras Arqueologia Geral e Arqueologia das Américas, até então vinculadas ao Departamento de Filosofia e Ciências Sociais, passaram para o Departamento de Estudos e Processos Museológicos, o que resultou na realização de um concurso público para contratação de professor efetivo, na alteração dos nomes (mas não das ementas) das disciplinas Arqueologia Geral (para Arqueologia e Museus) e Arqueologia Pré-Hispânica (para Museus e Arqueologia das Américas) e na ênfase no tratamento dos temas relacionados à área de interseção entre Arqueologia e Museologia, como as problemáticas relacionadas à preservação e à extroversão do patrimônio arqueológico.

Finalmente, quanto aos professores responsáveis pelas cadeiras de Arqueologia, três merecem destaque, sendo o primeiro o Professor João Angyone Costa, primeiro professor de Arquelogia no Curso de Museus, lecionando a disciplina de 1932 a 1944, por 12 anos; o Professor Diógenes Vianna Guerra, que lecionou a disciplina Arqueologia Brasileira para Museus Históricos e Arqueologia Brasileira/ Arte Indígena/ Arte Popular para Museus Artísticos nos anos de 1946, 1949 e de 1952 a 1969, e depois lecionou a disciplina de Arqueologia de 1970 a 1972 e as disciplinas Arqueologia I e II de 1973 a 1975, conforme as mudanças nas grades curriculares, atuando como professor no 
Curso de Museus por 24 anos; e a Professora Marilda Monteiro Gomes da Silva, que lecionou as disciplinas de Arqueologia I e II de 1978 a 1996 e depois a disciplina de Arqueologia Geral de 1997 a 2000, atuando no curso de Museologia por 22 anos.

Esta etapa do estudo evidenciou um personagem que, embora não fosse professor do curso de Museologia, contribuiu para o desenvolvimento da Arqueologia e para a valorização e proteção do patrimônio arqueológico no país - e exigiu ampliar o levantamento bibliográfico e documental para os fundos sob a guarda do Arquivo Histórico do Museu de Astronomia e Ciências Afins (MAST/MCTI). Luiz de Castro Faria, bacharel em Museologia, aluno de Angyone Costa, durante a década de 1930 foi estagiário de Heloisa Alberto Torres, então diretora do Museu Nacional. Nessa instituição de excelência teve a oportunidade de se aproximar mais dos temas caros a essa disciplina em construção. Foi o responsável pela primeira escavação realizada em um sambaqui (Cabeçuda, em Laguna, litoral sul de Santa Catarina) a partir de um projeto com metodologia científica. Dito em outras palavras, Castro Faria, em duas campanhas, realizadas em 1950 e 1951, à luz de um conjunto de questões e hipóteses de trabalho, registrou a estratigrafia do sítio, bem como recuperou materiais associados a mais de cem contextos funerários (CASTRO FARIA, 1959; 2009). Castro Faria dedicou boa parte de sua vida à consolidação da Arqueologia no país refletindo profundamente sobre a prática desenvolvida e sobre os resultados alcançados (CASTRO FARIA, 1989), promovendo o intercâmbio entre arqueólogos brasileiros, estadunidenses e franceses e apoiando a realização de cursos de formação, dentre inúmeras atividades - e com igual afinco à valorização e proteção do patrimônio arqueológico brasileiro. A soma de seus esforços 
com os de outros personagens-chave para a preservação dos sítios arqueológicos, nomeadamente Paulo Duarte e Loureiro Fernandes, resultou na criação da Lei no 3.924, de 26 de julho de 1961, que dispõe sobre a proteção do patrimônio arqueológico brasileiro (SALADINO, 2010).

\section{Considerações finais}

Os museus estão em voga nos tempos de sedução da memória (HUYSSEN, 2000) e da modernidade líquida, onde a cultura tem clientes a seduzir (BAUMAN, 2013:21); por isso tais instituições necessitam, além de atender e satisfazer muitas e diversas demandas, criar novas necessidades. Para além da preservação e da conservação do patrimônio museológico e da produção de novos sentidos aos referenciais patrimoniais, espera-se o planejamento e oferta de serviços de qualidade com vistas ao empoderamento e à mudança social, mas também ao lazer. Em outras palavras, os museus, mais que templosdepósitos das coisas valiosas, são processos-instituições comprometidas com a formação dos indivíduos-cidadãos e, mesmo indivíduos-consumidores de cultura (BAUMANN, 2013).

Os processos relacionados à valorização, preservação e socialização do patrimônio apoiam-se nos campos jurídico-legal, científico, econômico, político e social. Uma vez que o patrimônio é percebido como elemento de reconhecimento e de desenvolvimento social, espera-se dos profissionais responsáveis pela dinâmica da cadeia operatória da museologia a capacidade de trabalhar com as potencialidades e rugosidades das distintas perspectivas sobre os bens. Nesse sentido, acreditamos que estudar e compreender as bases formativas dos museólogos - no caso deste estudo relacionadas à sua atuação sobre o patrimônio 
arqueológico - pode lançar luzes sobre as práticas dos museólogos no tocante à preservação do patrimônio arqueológico em uma conjuntura na qual se observa o crescimento exponencial de material arqueológico sob a guarda dos museus em decorrência do desenvolvimento da arqueologia empresarial no país (SALADINO, 2010; WICHERS, 2010; SALADINO et al, 2013).

Voltando ao estudo apresentado neste artigo, diante do repertório de documentos analisados, consideramos a a Arqueologia é uma disciplina de importância para a formação dos museólgos, pois permanece presente na grade de cadeiras obrigatórias do curso de Museologia mais antigo do país, desde sua criação, em 1932. Independente das modificações curriculares, os discentes de Museologia sempre tiveram contato com os conteúdos de Arqueologia e sua relação com os museus e com o patrimônio integral como um todo. Entretanto, compreendemos que tal importância não se refere simplesmente à presença da Arqueologia na grade curricular, mas, principalmente, no esforço empreendido em manter atualizado o conteúdo programático par i passu com o desenvolvimento do campo da Arqueologia e em dar ênfase nos aspectos convergentes entre as disciplinas, relacionados às problemáticas da preservação e da gestão do patrimônio arqueológico. Acreditamos que o egresso do Curso de Museus do MHN, Luiz de Castro Faria, representa e sintetiza os objetivos estratégicos do primeiro curso Museologia do Brasil, designadamente a formação de profissionais capazes de transpor as fronteiras disciplinares, eventualmente se especializarem em outras áreas, mas sempre com o fito de contribuir para o desenvolvimento e consolidação das políticas de preservação do patrimônio cultural. 
Assim sendo, à luz das análises realizadas ao longo da investigação, compreendemos que:

- há um esforço em preparar profissionais de Museologia para enfrentarem os desafios e especificidades da preservação do patrimônio arqueológico musealizado;

- a formação em Museologia pode contribuir para com a ressignificação e valorização do patrimônio arqueológico na medida em que os conteúdos programáticos do campo do patrimônio e, mais especificamente, da área da comunicação em museus são articulados com os conteúdos das disciplinas que discutem sobre a preservação desta categoria de bem cultural;

- o desafio do crescimento exponencial das coleções arqueológicas precisa ser discutido em toda a sua complexidade e especificidade nas cadeiras dedicadas à cadeia operatória da museologia, designadamente aquelas que tratam de atividades como documentação, conservação e comunicação;

- a gestão do patrimônio cultural é tema que necessita de uma abordagem transdisciplinar e

- os profissionais de Museologia em formação aproximam-se das áreas de interseção entre os campos disciplinares, neste caso, do espaço híbrido no qual se desenvolve a socialização do patrimônio arqueológico.

Com o intuito de avaliar o estudo ora apresentado, elencamos os pontos positivos da realização do estudo. É possível destacar como um ponto positivo deste estudo a sua vinculação ao Grupo de Investigação "Memória e Preservação da Museologia no Brasil", pois tal conexão permite que a reflexão sobre o lugar da Arqueologia no Curso de Museologia não se esgote nela mesma. Em outras palavras, há a possibilidade de prosseguir com o levantamento de dados sobre os professores 
que ministraram as cadeiras de Arqueologia e egressos do curso que se dedicaram à prática da arqueologia e à preservação do patrimônio arqueológico.

Outro aspecto positivo do estudo refere-se à possibilidade de identificar pontos de convergência na formação do museólogo e do arqueólogo no tocante à preservação e socialização do patrimônio arqueológico de maneira geral e à gestão das coleções arqueológicas.

Ademais, o desenvolvimento desta investigação, concentrada em um aspecto da memória da Escola de Museologia da UNIRIO, pode trazer outras perspectivas para o Projeto Memória da Museologia como, por exemplo, a reflexão, a partir de um recorte específico, sobre as especificidades e desenvolvimento do próprio curso sobre o uma perspectiva eminentemente e efetivamente interdisciplinar na formação do museólogo e a composição de um panorama sobre o desenvolvimento e alteração dos conteúdos programáticos de um rol específico de cadeiras (voltadas para a Arqueologia), fundamental para a análise da transformação da formação do museólogo frente às demandas conjunturais do mundo dos museus e dos patrimônios.

Por fim, ressaltamos que o estudo pode apresentar desdobramentos, como o levantamento e análise dos conteúdos programáticos das cadeiras de arqueologia dos cursos de Museologia que tiveram como modelo o projeto da escola de Museologia da UNIRIO. Assim seria possível, além de estabelecer um quadro comparativo das disciplinas, identificar possíveis diferenças relacionadas a demandas da gestão do patrimônio arqueológico local ou regional. 


\section{Agradecimentos}

Agradecemos ao Prof. Dr. Ivan Coelho de Sá e toda a sua equipe do Grupo de Investigação "Memória e Preservação da Museologia no Brasil" pelo inestimável apoio ao desenvolvimento deste estudo.

\section{Referências}

BAUMAN, Zigmunt. (2013). A cultura no mundo líquido moderno. Rio de Janeiro: Zahar Editor.

BRUNO, Cristina. (1999). O esquecimento das fontes arqueológicas: a estratrigrafia do abaono e as trincheiras da arqueologia. Cadernos de Sociomuseologia, N.17, 17-33.

BRUNO, Cristina. (2005). Arqueologia e antropofagia: a musealização de sítios arqueológicos. Revista do Patrimônio Histórico e Artístico Nacional. no 31. Brasília: IPHAN/MinC, 235247.

CASTRO FARIA, Luiz de. (1959). O problema da proteção dos sambaquis. Arquivos do Museu Nacional, vol. XLIX, Rio de Janeiro, Museu Nacional, 95-137.

CASTRO FARIA, Luiz de. (1989) Domínios e fronteiras do saber: a identidade da Arqueologia. Dédalo, São Paulo, 1, 26-39.

CASTRO FARIA, Luiz de. (1999) Antropologia: escritos exumados. Rio de Janeiro: EdUFF.

CHAGAS, Mario de Souza. (2006) Há uma gota de sangue em cada museu: a ótica museológica de Mário de Andrade. Chapecó: Argos.

COSTA, Angyone. (1936) Archeologia Geral. Civilizações da América Pré-Colombiana Antiguidade Clássica, Civilizações Orientaes. São Paulo: Companhia Editora Nacional,. 
COSTA, Angyone. (1934) Introdução à Arqueologia Brasileira. Etnografia e História. Edição ilustrada. Biblioteca Pedagógica Brasileira, Série V; Brasiliana, vol. XXXIV. São Paulo: Cia Editora Nacional.

FONSECA, Maria Cecília Londres. (2005) O patrimônio em processo: trajetória da política federal de preservação no Brasil. Rio de Janeiro: Editora UFRJ; MinC - Iphan.

GONÇALVES, José Reginaldo. (2002). A retórica da perda. Rio de Janeiro: Editora UFRJ.

NORA, Pierre. (1993) Entre memória e história: a problemática dos lugares. Projeto História, n10, São Paulo: PUC, 7-28.

PROUS, André. Arqueologia Brasileira. BSB; EdunB, 1992.

SALADINO, Alejandra (2010). Prospecções: o patirmônio arqueológico nas práticas e trajetória do Iphan. Tese de Doutoramento. Rio de Janeiro: Universidade do Estado do Rio de Janeiro.

SCHWARCZ, Lilia Moritz. (1993) O Espetáculo das Raças cientistas, instituições e questão racial no Brasil 1870-1930. São Paulo: Companhia das Letras.

WICHERS, Camila Azevedo de Moraes. Museus e os descaminhos do patrimônio arqueológico: (des)caminhos da prática brasileira. (2010). Tese de doutoramento. Lisboa: Universidade Lusófona de Humanidades e Tecnologias.

\section{Outras fontes}

BRUNO, Cristina; ZANETTINI, Paulo (orgs.). (2007). Relatório do Simpósio O futuro dos acervos do XIV Encontro Nacional da Sociedade de Arqueologia Brasileira, Florianópolis, Universidade Federal de Santa Catarina. 
SÁ, Ivan Coelho de; TOSTES, Gustavo Oliveira. (2011/2012). Leis, Decretos, Pareceres, Resoluções, Portarias, Ofícios, Estatutos, Regimentos e Outros. Vol. II ao XI. Rio de Janeiro: Universidade Federal do Estado do Rio de Janeiro.

SÁ, Ivan Coelho de; TOSTES, Gustavo Oliveira. (2012/2013). Matrizes Curriculares do Curso de Museologia da UNIRIO. Vol. I ao XV. Rio de Janeiro: Universidade Federal do Estado do Rio de Janeiro. 
